\title{
Retraction Note to: Filter Bank Multicarrier Based Generalized Discrete Fourier Transform for Peak to Average Power Ratio Reduction
}

\author{
B. Ramesh ${ }^{1} \cdot$ J. Senthilkumar ${ }^{2} \cdot$ Y. Suresh ${ }^{2} \cdot$ V. Mohanraj $^{2}$ \\ Published online: 26 June 2020 \\ (C) Springer Science+Business Media, LLC, part of Springer Nature 2020
}

Retraction Note to: Mobile Networks and Applications (2019) 24:1793-1803

https://doi.org/10.1007/s11036-019-01391-8

The authors have retracted this article [1] as it overlaps significantly with a previously published article by Aboul-Dahab et al. [2]. All authors agree with this retraction.

[1] B. Ramesh, J. Senthilkumar, Y. Suresh \& V. Mohanraj. Filter Bank Multicarrier Based Generalized Discrete Fourier Transform for Peak to Average Power Ratio Reduction. Mobile Netw Appl 24, 1793-1803 (2019). https://doi.org/ 10.1007/s11036-019-01391-8

[2] Mohamed Aboul-Dahab, Mohamed M. Fouad and Radwa A.Roushdy. Generalized Discrete Fourier Transform For FBMC Peak to Average Power Ratio Reduction. IEEE Access 2019 vol 7, pp. 81730-81740. https://doi.org/10. 1109/ACCESS.2019.2921447

Publisher's Note Springer Nature remains neutral with regard to jurisdictional claims in published maps and institutional affiliations.

The online version of the original article can be found at https://doi.org/ 10.1007/s11036-019-01391-8

B. Ramesh

mailrameshece@gmail.com

J. Senthilkumar

jsenthi110@gmail.com

Y. Suresh

sureshy@sonatech.ac.in

V. Mohanraj

vmohanraj06@gmail.com

1 Department of Electronics and Communication Engineering, Annapoorana Engineering College, Salem, Tamilnadu, India

2 Department of Information Technology, Sona College of Technology, Salem, Tamilnadu, India 